Research Article

\title{
Genome-wide characterization of the NRAMP gene family in Phaseolus vulgaris provides insights into functional implications during common bean development
}

\author{
Juliane Karine Ishida ${ }^{1}$, Danielle G. G. Caldas ${ }^{1}$, Lucas Roberto Oliveira ${ }^{1}$, Gabriela Campos Frederici ${ }^{1}$, Lucas \\ Margato Pereira Leite ${ }^{1}$ and Tsai Siu Mui ${ }^{1}$ \\ ${ }^{1}$ Centro de Energia Nuclear na Agricultura, Universidade de São Paulo (CENA-USP), Piracicaba, SP, \\ Brazil.
}

\begin{abstract}
Transporter proteins play an essential role in the uptake, trafficking and storage of metals in plant tissues. The Natural Resistance-Associated Macrophage Protein (NRAMP) family plays an essential role in divalent metal transport. We conducted bioinformatics approaches to identify seven NRAMP genes in the Phaseolus vulgaris genome, investigated their phylogenetic relation, and performed transmembrane domain and gene/protein structure analyses. We found that the NRAMP gene family forms two distinct groups. One group included the PVNRAMP1, -6 , and -7 genes that share a fragmented structure with a numerous exon/intron organization and encode proteins with mitochondrial or plastidial localization. The other group is characterized by few exons that encode cytoplasmic proteins. In addition, our data indicated that PVNRAMP6 and -7 may be involved in mineral uptake and mobilization in nodule tissues, while the genes PVNRAMP1, -2, -3, -4 and -5 are potentially recruited during plant development. This data provided a more comprehensive understanding of the role of NRAMP transporters in metal homeostasis in $P$. vulgaris.
\end{abstract}

Keywords: Phaseolus vulgaris, transporter, NRAMP, gene family, phylogenetic analysis.

Received: September 05, 2017; Accepted: February 20, 2018.

\section{Introduction}

The common bean (Phaseolus vulgaris L.) is one of the most consumed crops worldwide (www.fao.org/faostat). It is rich in protein, carbohydrates, and minerals (Gepts et al., 2008) and its frequent consumption may prevent illnesses like cardiovascular diseases (Bouchenak and Lamri-Senhadji, 2013), colon cancer (Bennink, 2002), and diabetes (Geil and Anderson, 1994). In the developing world, bean is a main source of nutrition. For example, in sub-Saharan Africa, one of the most critical areas for food security, beans represent $15 \%$ of the calories and $36 \%$ of the proteins in dairy supplies (www.fao.org/faostat). In Latin America, the per capita beans consumption is around $16 \mathrm{~kg} /$ year (Broughton et al., 2003). The nutritional benefits of consuming beans require a deeper understanding of the molecular mechanisms involved in nutrient accumulation and mobilization in plant tissues, especially in the seeds.

The identification of a specific set of transporters that provides the fine balance of metal concentration across the cellular membrane is essential to understanding the physio-

Send correspondence to Juliane Karine Ishida. Laboratório de Biologia Celular e Molecular, CENA-USP, Av. Centenário 303, 13416-000 Piracicaba, SP, Brazil. E-mail: julianeishida@gmail.com logical function of these elements in plant development (Dordas, 2008). One relevant transporter family is NRAMP (Natural Resistance-Associated Macrophage Protein). NRAMP genes encode integral membrane proteins responsible for the transport of divalent metals across the cellular membrane. The NRAMP family is highly conserved from bacteria to mammals, showing a preserved consensus motif and 10-12 transmembrane domains (Cellier et al., 1995). The emergence of NRAMPs occurs parallel to the increase in atmospheric oxygen content (Cellier et al., 2001), and it may have evolved from the LeuT superfamily cationdriven transporter (Cellier 2012) in a putative anaerobic prokaryote ancestor, probably close to the Chlorobium group (Cellier et al., 2001). In prokaryotes, the biological function of NRAMP is associated with defense and nutrition (Nevo and Nelson, 2006), while in animals the primary function of NRAMP lies in the maintenance of iron homeostasis (Gunshin et al., 2001; Iolascon and De Falco, 2009; Shawki et al., 2012; Victoria et al., 2012). The plant NRAMP family is responsible for keeping the right balance of divalent ions $\left(\mathrm{Fe}^{2+}, \mathrm{Mn}^{2+}, \mathrm{Cu}^{2+}\right.$, and $\mathrm{Zn}^{2+}$ ) (Sebastien and Schroeder, 2004; Victoria et al., 2012) and the trivalent $\left(\mathrm{Al}^{3+}\right)$ ion (Xia et al., 2010) across the plasma and vascular membranes. Phylogenetic data revealed the existence of two NRAMP subgroups (Sebastien and Schroeder 2004): one obtained from a bacterial genome during the endosym- 
biotic process that originated double-membrane organelles; and another group that shares high amino acid identity/similarity with proteins found in the animal genome, raising the hypothesis of multiple origins of the NRAMP family (Sebastien and Schroeder, 2004).

There are six NRAMP genes in Arabidopsis (Thomine et al., 2000). Mutants missing the vacuole membrane proteins AtNRAMP3 and -4 show a reduction in germination rate under iron deficient conditions (Lanquar et al., 2005) and an impairment in photosynthesis capacity if manganese is limited (Lanquar et al., 2010). Additionally, AtNRAMP1 is a key transporter for iron homeostasis $(\mathrm{Cu}-$ rie et al., 2000). Rice contains seven members of the NRAMP family (Belouchi et al., 1997). OsNRAMP1 translocates the beneficial $\mathrm{Fe}^{2+}$ and also the toxic arsenic $\left(\mathrm{As}^{3+}\right)$ and cadmium $\left(\mathrm{Cd}^{2+}\right)$ in rice (Takahashi et al., 2011; Tiwari et al., 2014). The transporters OsNRAMP4 and OsNRAMP5 play a role in the intracellular mobilization of $\mathrm{Al}^{3+}$ (Xia et al., 2010) and $\mathrm{Mn}^{2+} / \mathrm{Cd}^{2+}$ (Ishimaru et al., 2012), whereas OsNRAMP3 is present in conducting vascular cells and responsible for allocating $\mathrm{Mn}^{2+}$ from source to sink tissues. Apparently, OsNRAMP3 does not act in $\mathrm{Fe}^{2+}$ translocation (Yamaji et al., 2013). Similarly, the HvNRAMP5 in barley enables the uptake of $\mathrm{Mn}^{2+}$ and the toxic $\mathrm{Cd}^{2+}$, but not of $\mathrm{Fe}^{2+}$ (Wu et al., 2016). In the hyper accumulating species Thlaspi caerulescens and Thlaspi japonicum, the NRAMP protein is responsible for mobilizing the heavy metals $\mathrm{Cd}^{2+}$ and $\mathrm{Ni}^{2+}$ in plant tissues (Mizuno et al., 2005; Oomen et al., 2009).

A synapomorphic trait of Fabaceae is the symbiotic association with nitrogen-fixing bacteria at specialized root organs, the nodules (Gage, 2004). There are two types of nodules in leguminous plants with different developmental strategies. The determinate type found in P. vulgaris and soybean (Glycine max) roots is characterized by a spherical shape due to the reduction of activity in meristematic tissues shortly after nodule initiation (Gage, 2004). The indeterminate nodules present in roots of Medicago truncatula and peas have a typically elongated shape. The meristematic region is continuously producing new cells along the active period of the nodule, generating different zones related to the developmental stage of symbiotic bacterial cells (bacterioid) (Jones et al., 2007). In Zone I, the meristem actively forms new nodule tissues. In Zones II and III occur the infection and nitrogen fixation, and in Zone IV (closer to the root) the bacteroid starts to degenerate (Jones et al., 2007). A better comprehension of nodule formation may provide insights towards employing bacteria to increase the availability of nitrogen in the soil, hence reducing the need for fertilizers. Iron is a required micronutrient for establishing symbiosis with nitrogen-fixing bacteria, since it is a cofactor of the enzyme nitrogenase recruited for atmospheric nitrogen uptake (Brear et al., 2013). In $M$. truncatula, the protein MtNRAMP1 presented high expression in the nodule region, acting as an iron transporter across the plasma membrane during nodulation (Tejada-
Jiménez et al., 2015). In G. max, a NRAMP member (GmDMT1) located in the symbiosome membrane is responsible for the iron absorption in rhizobia-symbiotic tissues (Kaiser et al., 2003). Thus, the NRAMP transporters are apparently of relevance in the import of nutrients for nodule formation, regardless of whether they are of a determinate or indeterminate type.

The availability of a fully sequenced genome for common bean provides opportunities to characterize gene transporter families and to identify their potential roles in uptake, allocation and storage of soil minerals in plant tissue. A better understanding of dynamics metal ions is an important step to improve crop breeding. So far, information on the major proteins involved in the transport of metals in common bean remains incipient. Here we identified and characterized seven homologs of NRAMP transporters in $P$. vulgaris. The gene structure, chromosomal distribution, phylogenetic tree, and the expression of NRAMP homologs were investigated using bioinformatics approaches. The results obtained contribute to comprehend the biological role of the players involved in metal homeostasis during $P$. vulgaris development.

\section{Material and Methods}

\section{Identification and annotation of NRAMP genes in $P$. vulgaris genome}

The keyword NRAMP was used to search the Phytozome database (http://www.phytozome.net) in the Arabidopsis thaliana genome (TAIR10). AtNRAMP sequences were identified and used as query to identify their protein homologs in the $P$. vulgaris genome (G19833). All sequences with a similarity score above $50 \%$ were considered. To search for $P$. vulgaris NRAMP genes we used the web tool TMHMM server (http://cbs.dtu.dk)(Krogh et al., 2001) to predict transmembrane domains in putative protein sequences and the TargetP 1.1 Server (Emanuelsson et al., 2007) for the prediction of subcellular localization. The general information of NRAMP genes, including the genomic, cDNA, and coding sequences, protein length, etc., were extracted from the Phytozome website (www.phytozome.jgi.doe.g.,ov). The exon/intron organization was accessed using the online tool GSDS 2.0 (http://gsds.cbi.pku.edu.cn) (Hu et al., 2015), and the similarities among exons were compared using the BLASTN algorithm (Altschul 1997). The $\mathrm{Ka} / \mathrm{Ks}$ ratio was calculated using the option Compute Pairwise Distances in MEGA7 software (Kumar et al., 2016); the analysis was conducted using the Nei-Gojobori Method with all the positions containing gaps and missing values eliminated.

\section{Chromosome distribution, syntenic and regulatory elements analysis of common bean NRAMP genes}

The chromosomal localization and putative promoter regions ( $3 \mathrm{~kb}$ from ATG site) of $P v N R A M P$ genes were extracted using the software GENEIOUS $\AA$ 
(www.geneious.com). All figures were edited using the Adobe Illustrator package. The cis-elements of promoter sequences and IRE motifs were identified by PlantCARE (Lescot et al., 2002) and SIRE programs (Campillos et al., 2010), respectively, under default parameters.

\section{Model structure and phylogenetic tree construction of NRAMPs}

The putative protein sequences were aligned using the CLUSTALW (Thompson et al., 2002) algorithm with default settings, and the phylogenetic trees were generated using MEGA7 software (Kumar et al., 2016) with the Maximum Likelihood statistical method set to a 10,000 bootstrap value. Protein structures of NRAMPs were predicted using the Swiss-model software based on data of the Staphylococcus capitis divalent ion transporter (DMT) complex with manganese (ID: 4wgw.1). Putative models were visualized and edited using the Ras Top Molecular Visualization Software (www.geneinfinity.org/rastop).

\section{RNA-Seq analysis of NRAMP genes}

The gene expression atlas data was obtained from the website www.plantgrn.noble.org/PvGEA. The expression levels were obtained from the Phytozome website, and RNA-Seq data of $P$. vulgaris embryo were retrieved from public database under the code GSE57535. To download the large dataset in Phytozome a login and password were created for access to the JG1 genome portal, and the latest version of the $P$. vulgaris transcriptome was downloaded for analysis $(P$. vulgaris_442_ver2.1). Heatmaps were generated using the GenePattern 2.0 program (Reich et al., 2006) with a hierarchical algorithm. Distance measures for column and raw clustering were performed using the Pearson's correlation coefficient (absolute value) with the Pairwise Average-Linkage method, which calculates the distance between two clusters based on the average distance between elements located in the two clusters. Expression levels of NRAMP genes in M. truncatula were obtained from PLEXdb (www.plexdb.org), a database for gene expression resources for plants and pathogens.

\section{P. vulgaris infection by Colletotrichum lindemuthianum.}

Colletotrichum lindemuthianum (race 73) was cultivated in MATHUR medium $(8 \mathrm{~g} / \mathrm{L}$ dextrose, $2.5 \mathrm{~g} / \mathrm{L}$ $\mathrm{MgSO}_{4} .7 \mathrm{H}_{2} \mathrm{O}, 2.7 \mathrm{~g} / \mathrm{L} \mathrm{KK_{2 }} \mathrm{PO}_{4}, 2.4 \mathrm{~g} / \mathrm{L}$ peptone, $2 \mathrm{~g} / \mathrm{L}$ yeast extract, and $16 \mathrm{~g} / \mathrm{L}$ agar) at $28{ }^{\circ} \mathrm{C}$ in darkness until sporulation. The medium surface was scraped with the aid of a Drigalsky loop and the spores suspended in $40 \mathrm{~mL}$ of sterile Milli-Q water containing 0.01\% (v/v) Tween 20. The spore concentration was adjusted to $1.0 \times 10^{6}$ cells $/ \mathrm{mL}$ using a Neubauer chamber. P. vulgaris seeds (genotype SEL1308) were immersed for $10 \mathrm{~min}$ in $10 \%(\mathrm{v} / \mathrm{v})$ sodium hypochlorite solution, followed by five washes with sterile water. The seeds were germinated on a wet filter paper in darkness. Plants were grown in a vermiculate/sand (1:1) substrate at $22{ }^{\circ} \mathrm{C}$ under a photoperiod of $16 \mathrm{~h} \mathrm{light} \mathrm{and} 8 \mathrm{~h}$ dark. First trifoliate leaves from 10-day-old seedlings were inoculated with a drop of the $C$. lindemuthianum spore suspension $\left(1.0 \times 10^{6}\right.$ cells $\left./ \mathrm{mL}\right)$. Simultaneously, the same number of plants was inoculated with a solution of $0.01 \%$ Tween 20 diluted in sterile water. Plants were covered with colorless and translucent plastic bags to keep the humidity close to $100 \%$. Inoculated-leaf pieces $(5 \times 5 \mathrm{~mm})$ were collected 65 hours after the fungal infection (65 hai), using a razor blade. They were immediately frozen in liquid nitrogen and stored at $-80{ }^{\circ} \mathrm{C}$. The experiment was conducted with biological triplicates.

\section{RNA extraction and qRT-PCR analysis}

Total RNA from all samples was extracted using a NucleoSpin RNA XS kit (Macherey-Nagel). First strand cDNAs were synthesized from $0.1 \mu \mathrm{g}$ of total RNA following the instructions for the MAXIMA First Strand cDNA synthesis kit (Fermentas). As internal control for the qRTPCR assays we used the primer pairs IDE and Act11 (Borges et al., 2012) which are specific for transcripts encoding an insulin degrading enzyme and actin, respectively. The primers for PvNRAMP genes were designed using Primer3Plus software (Untergasser et al., 2007) under default qPCR settings, as listed in Table S1. The qRT-PCR assays were carried out in a StepOnePlus Real Time PCR System (Applied Biosystems) using $5 \mu \mathrm{L}$ of SYBR ${ }^{\circledR}$ Green 2X Mix (Thermo-Fisher), $250 \mathrm{nM}$ of each primer and 100 ng of cDNA, in a total volume of $10 \mu \mathrm{L}$. The amplification condition was $95^{\circ} \mathrm{C}$ for $10 \mathrm{~min}, 40$ cycles of $95^{\circ} \mathrm{C}$ for $15 \mathrm{~s}$, $59^{\circ} \mathrm{C}$ for $20 \mathrm{~s}$ and $72{ }^{\circ} \mathrm{C}$ for $30 \mathrm{~s}$, A final step of $15 \mathrm{~s}$ at $95^{\circ} \mathrm{C}, 1 \mathrm{~min}$ at $59^{\circ} \mathrm{C}$ and fluorescence measure at each $0.7^{\circ} \mathrm{C}$ variation (from $60^{\circ} \mathrm{C}$ to $95^{\circ} \mathrm{C}$ ) was included to obtain the melting curve. Two to three technical replicates were performed.

To calculate the PvNRAMP relative expression, the raw data of fluorescence levels were submitted to LinRegPCR software (Ramakers et al., 2003) to establish the baseline correction and run a linear regression analysis on each amplification curve. Next, the optimal set of data points (Window-of-Linearity) was defined for each amplification data set to allow the calculation of the threshold and quantification cycle $(\mathrm{Cq})$ values for each sample. The reaction efficiency was calculated based on slope of the line $\left(\mathrm{E}=10^{\text {slope }}\right)$, considering an ideal value range $(1.8 \leq \mathrm{E} \leq 2)$ and a correlation of $\mathrm{R} \geq 0.995$. Expression comparisons were done using the Pair Wise Fixed Reallocation Randomization test (with bootstrap $=2000$ permutations), implemented in the Relative Expression Software Tool $\begin{array}{llll}\text { REST }^{\circ} \text { - } & 384 & \text { version }\end{array}$ (http://www.gene-quantification.info) as described by (Pfaffl et al., 2002). 


\section{Results}

Identification and classification of NRAMP genes in the $P$. vulgaris genome

Nine sequences were initially found in the $P$. vulgaris genome using as query the homologs of $A$. thaliana NRAMP genes. Among these, only seven genes carried the consensus residues GQSSTITGTYAGQFIMGGFLN (Figure 1a), a unique motif associated with the NRAMP metal transporter family (Cellier et al., 1995). To facilitate understanding we renamed the NRAMP homologs in $P$. vulgaris as PvNRAMP1 to -7. The corresponding Phytozome code, gene length, and protein length are summarized in Table 1. They encode putative proteins ranging from 507 to 554 amino acid residues in length, with an average of $58.5 \mathrm{kDa}$ of molecular mass and a deduced isoelectric point (pI) ranging from 4.81 to 7.89 (Table 1). The genes PvNRAMP1, -6, and -7 encode proteins with a basic $\mathrm{pI}$ and with plastid localization, while the genes PvNRAMP2, -3, -4 , and -5 generate a cytoplasmic protein with acid $\mathrm{pI}(\mathrm{Ta}-$ ble 1). Twelve transmembrane domains (TM) were verified for all the members, with $\mathrm{N}$ - and $\mathrm{C}$ - tails pointing to opposite sides of the plasma membrane for PvNRAMP2, and Cand N-terminal turned to the intracellular region for $P v N R A M P 5$ and the extracellular side for other PvNRAMPS (Figure 1b). For all the $P v N R A M P s$, the conservative motif was localized between TM 8 and 9 (Curie et al., 2000; Hall and Williams, 2003), placed between 401-418 and 431-453 aa, similar to previously characterized NRAMP genes in plants (Kaiser et al., 2003; Mizuno et al., 2005; Vatansever et al., 2016).

\section{Gene structure and chromosomal distribution of NRAMP gene in P. vulgaris}

To investigate the evolutionary relationship among NRAMP genes in $P$. vulgaris, their chromosome map was constructed (Figure 2). The PvNRAMP1, -3 and -4 genes were localized in chromosome 5,3 , and 2 , respectively. The genes $P v N R A M P 2$ and -7 were at chromosome 9, while $P v N R A M P 5$ and -6 were at chromosome 10 (Figure 2). The selection pressure acting on NRAMP genes was inferred from the ratio of non-synonymous (Ka) to synonymous (Ks) substitution values, and our data indicated that all the $P v N R A M P s$ were under evolutionary pressure showing on average a $1.5 \mathrm{Ka} / \mathrm{Ks}$ ratio. Additionally, the gene structures were compared among the PvNRAMPs. The organization of introns and exons indicated that NRAMP genes could be divided into two types (Figure 3). Type I was formed by 13 short exons with lengths ranging from 79 to $342 \mathrm{bp}$ and intron sizes of $76 \mathrm{bp}$ to $1018 \mathrm{bp}$. This group included PvNRAMP1, -6, and -7, with an average identity of approximately $86 \%$ at some significant sequences, with the highest identity equal to $100 \%$ and the lowest equal to $75 \%$. In addition, the fifth exon in PvNRAMPl had similarity to two

\section{a}
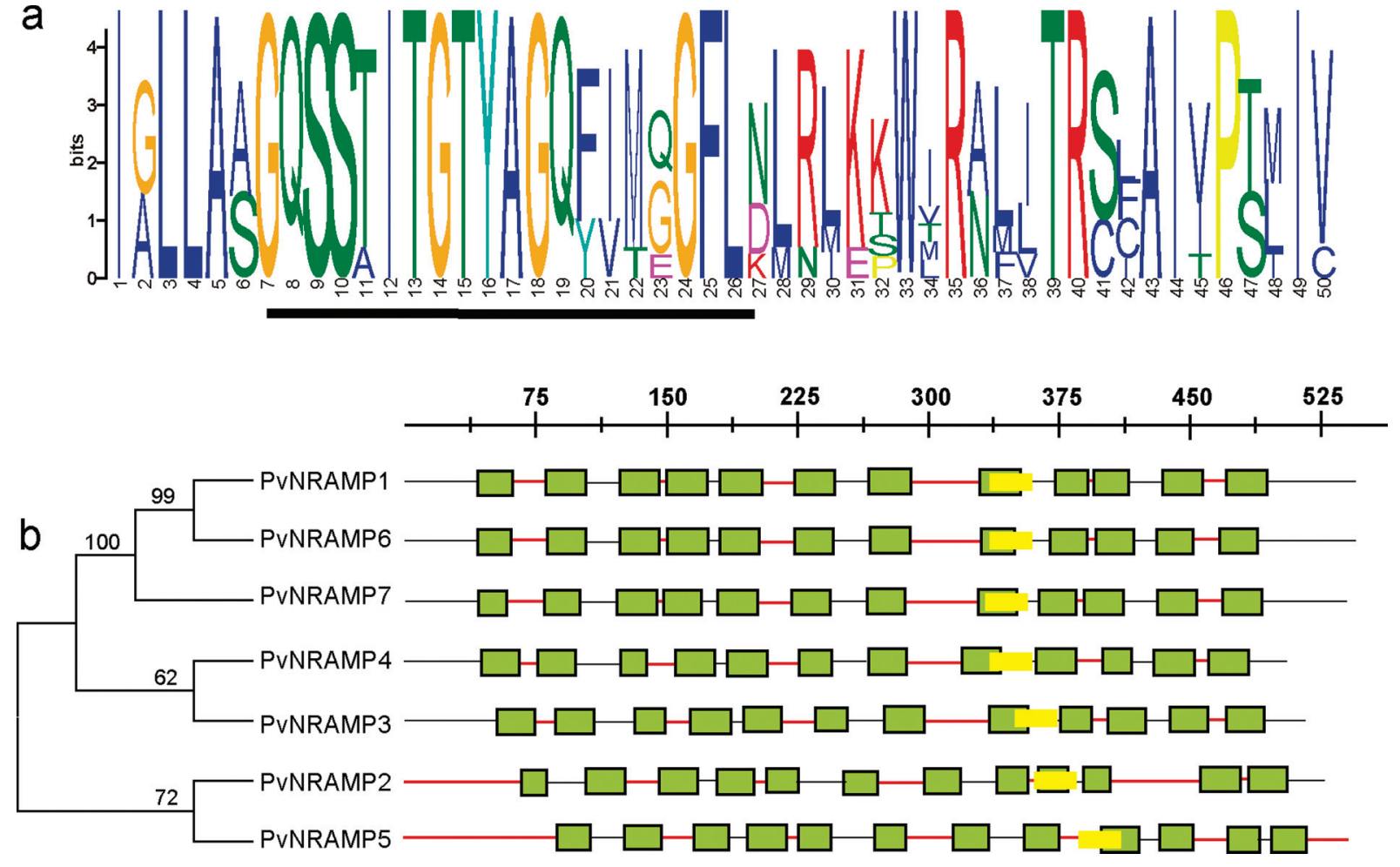

Figure 1 - Diagrammatic representation of architecture of the NRAMP putative protein in P. vulgaris. (a) The conserved motif graph generated by the MEME program, displayed by stacks of letters at each site. The conserved amino acid is marked by a yellow box at the bottom of stacked letters. (b) Schematic view of transmembrane domain (TM) (green), the extracellular and intracellular portions are represented in black and red lines, respectively. Conserved motif between TM 8 and 9 is shown in yellow. The scale is set to the number of amino acids. 


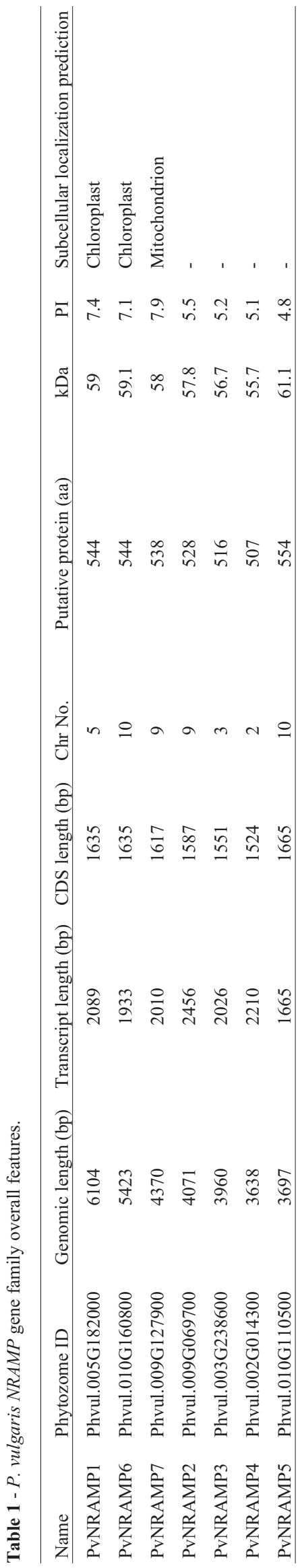

exons in PvNRAMP6, meaning that this exon was split into two coding sequence at the fifth and seventh exon position in PvNRAMP6. In another type formed by PvNRAMP4, -3, -2 , and -5 , the exon numbers were restricted to four, with high similarities among them and with exon lengths from $137 \mathrm{bp}$ to $653 \mathrm{bp}$ and intron lengths of $91 \mathrm{bp}$ to $1540 \mathrm{bp}$. To investigate if such exon-intron organization was conserved among NRAMPs, we analyzed 20 homologs in G. $\max , M$. truncatula, $A$. thaliana and $O$. sativa (Figure S1). AtNRAMP1 and -6 from Arabidopsis displayed 11 and 13 exons, respectively. OSNRAMP1, $-3,-4$, and -5 from rice and MtNRAMP1, -2, and -3 from M. truncatula showed 13 exons with limited size variation, while intron size varied largely (Figure S1). Type II grouped AtNRAMP2, -3, -4, and -5 from Arabidopsis, and the rice genes OsNRAMP2 and -6, MtNRAMP4, -5, -6, and -7 from M. truncatula, and GmDMT1 from G. max displayed preserved number and size of exons/introns (Figure S1). Our results indicated that two types of gene structure were conserved among NRAMP homologs.

\section{Phylogenetic comparison of PVNRAMP genes with their homologs in A. thaliana, O. sativa, G. max and M. truncatula}

To explore the phylogenetic association among NRAMP homologs in plant genomes, we generated a phylogenetic tree based on putative amino acid sequences of 30 NRAMPs from Arabidopsis, rice (Oryza sativa), M. truncatula and common bean. The tree topology indicated separation into two distinct groups (Figure 4). Each group contained sequences from different species, which suggests a close genetic conservation among them. Group I consisted of 12 members and their protein alignment showed that $26 \%$ of the amino acids were identical and localized at conserved positions. This group included previously characterized cation transporters, including AtNRAMP1 and OsNRAMP1, that are involved in the maintenance of iron homeostasis in Arabidopsis and rice, respectively (Curie et al., 2000; Takahashi et al., 2011), and the importer MtNRAMP1 that is required for the iron and manganese uptake by rhizobia-infected nodules in M. truncatula (Tejada-Jiménez et al., 2015). In several organisms, the absorption of manganese and iron occurs in an interdependent manner, using the same transport proteins (Fitsanakis et al., 2010). According to our data, the closest homolog of MtNRAMP1 in common bean was PvNRAMP7 (Figure 4) with $83 \%$ of shared amino acid identity. To investigate its association with metal transportation, the tertiary structure was predicted using bioinformatics tools. The PvNRAMP7 structure was modeled using Staphylococcus capitis DMT as template (Ehrnstorfer et al., 2014) (Figure 5a). The quality of property combinations between target and template was estimated by GMQE (Global Model Quality Estimation), resulting in a score of 0.56 . The predicted structure showed 12 transmembrane domains (Figure 5a) and potential Mg-coordinating amino acids at the positions Asp60, 


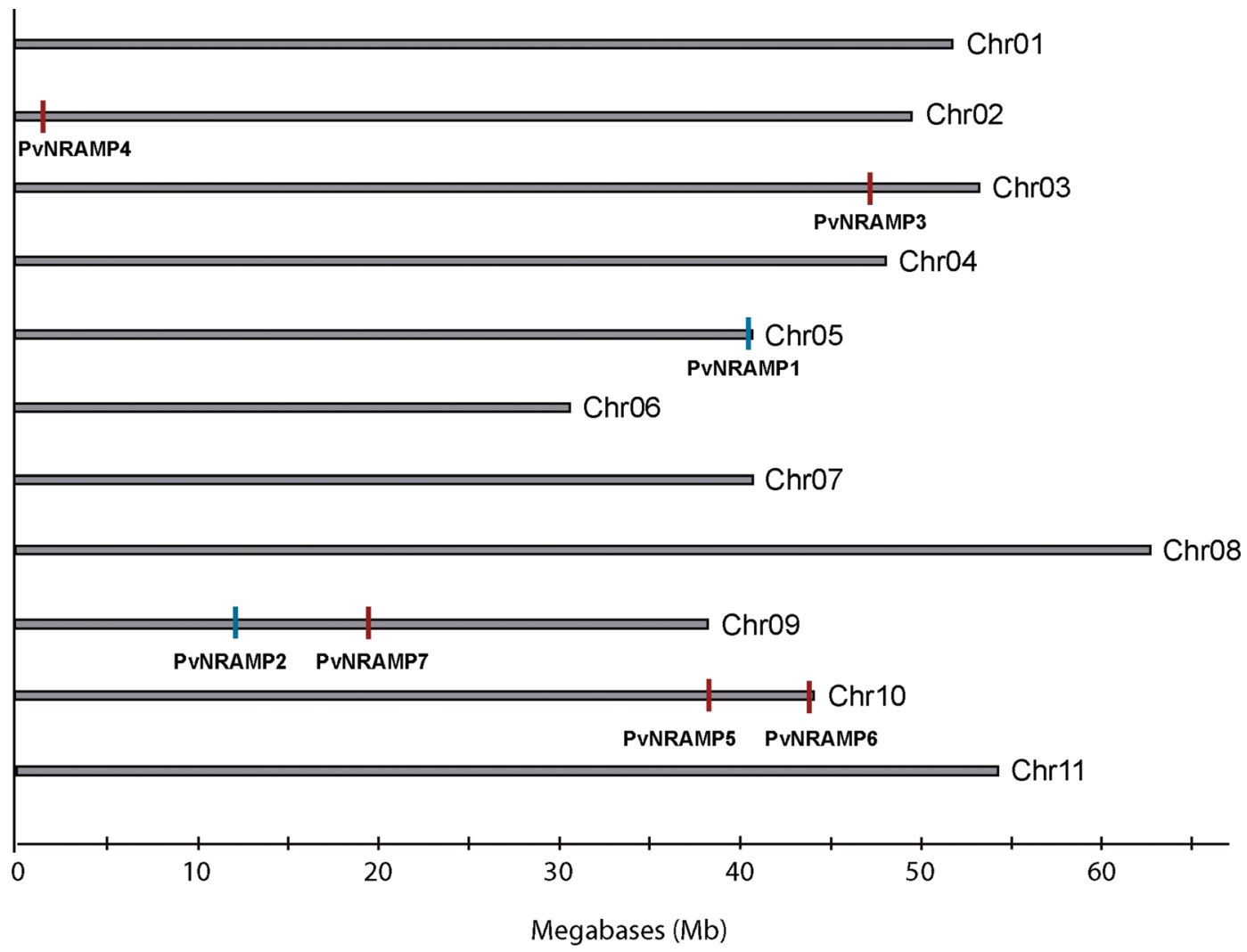

Figure 2 - Distribution of genes in $P$. vulgaris chromosome. Chromosome size is indicated by its relative length. The scale on the bottom is shown in megabases $(\mathrm{Mb})$. The blue bars mark the gene location at the forward direction, while the red bars mark the gene at the reverse position. The figure was generated by Geneious software and edited using the package Adobe Illustrator.

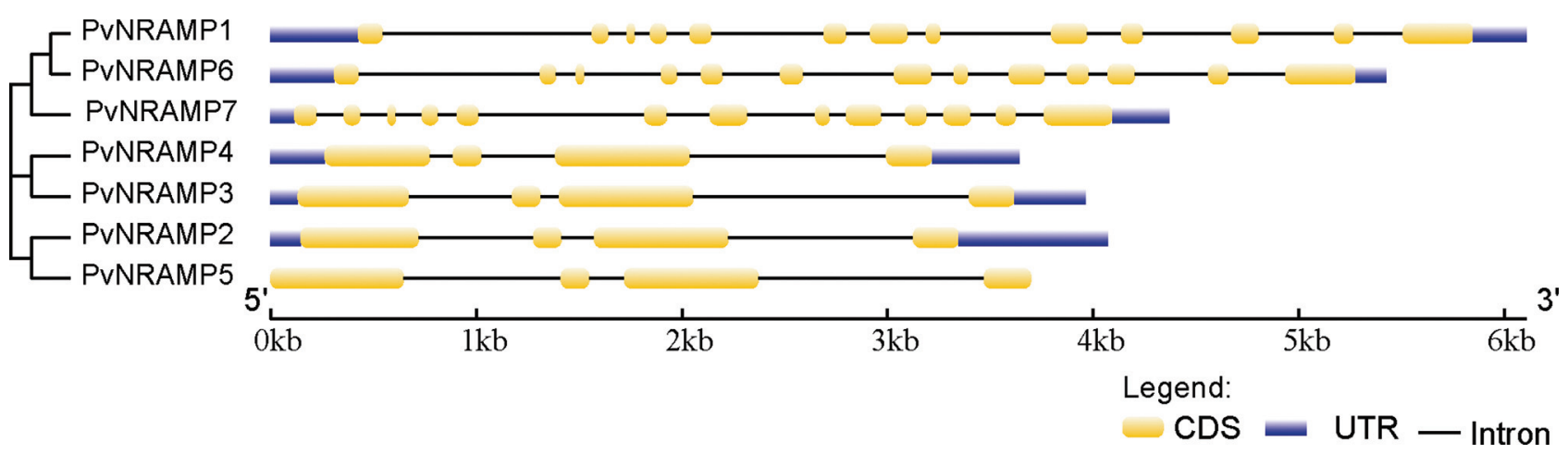

Figure 3 - Schematic structure of $P v N R A M P$ in $P$. vulgaris. Phylogenetic tree with introns, exons and UTRs. Lines connected to similar exons and different colors indicate novel exons. The phylogenetic tree was generated based on the Maximum Likelihood statistical method and the phylogenetic tree must show the numbers at the internal nodes.

Asn63, Ala232 and Met235 (Figure 5b). Results analogous to those found in MtNRAMP1 (Tejada-Jiménez et al., 2015) were observed for PvNRAMP1 (Figure S2a) and -6 (Figure S2b), which shared $58 \%$ of amino acid identity with MtNRAMP1. Therefore, our data suggest that these genes might play a role in iron homeostasis and potentially also for manganese transport in P. vulgaris. Group II consisted of 18 sequences, sharing $38.2 \%$ of identical amino acids located at conserved positions across the members. This group included $P v N R A M P 3$ and -4 , which were grouped with the GmDMT1 (Figure 4), a transporter from soybean involved in the nodulation process (Kaiser et al., 2003). PvNRAMP5 was closer to the transporter AtNRAMP5 (Figure 4) that negatively responds to higher concentrations of iron in flowers (Ravet et al., 2009). PvNRAMP2 and -4 were placed at the same branch as MtNRAMP4 and -5 (Figure 4), respectively, the functions of which have not yet been characterized. None of the PvNRAMP sequences showed enough affinity to the vacuolar transporters AtNRAMP3 and -4 . 


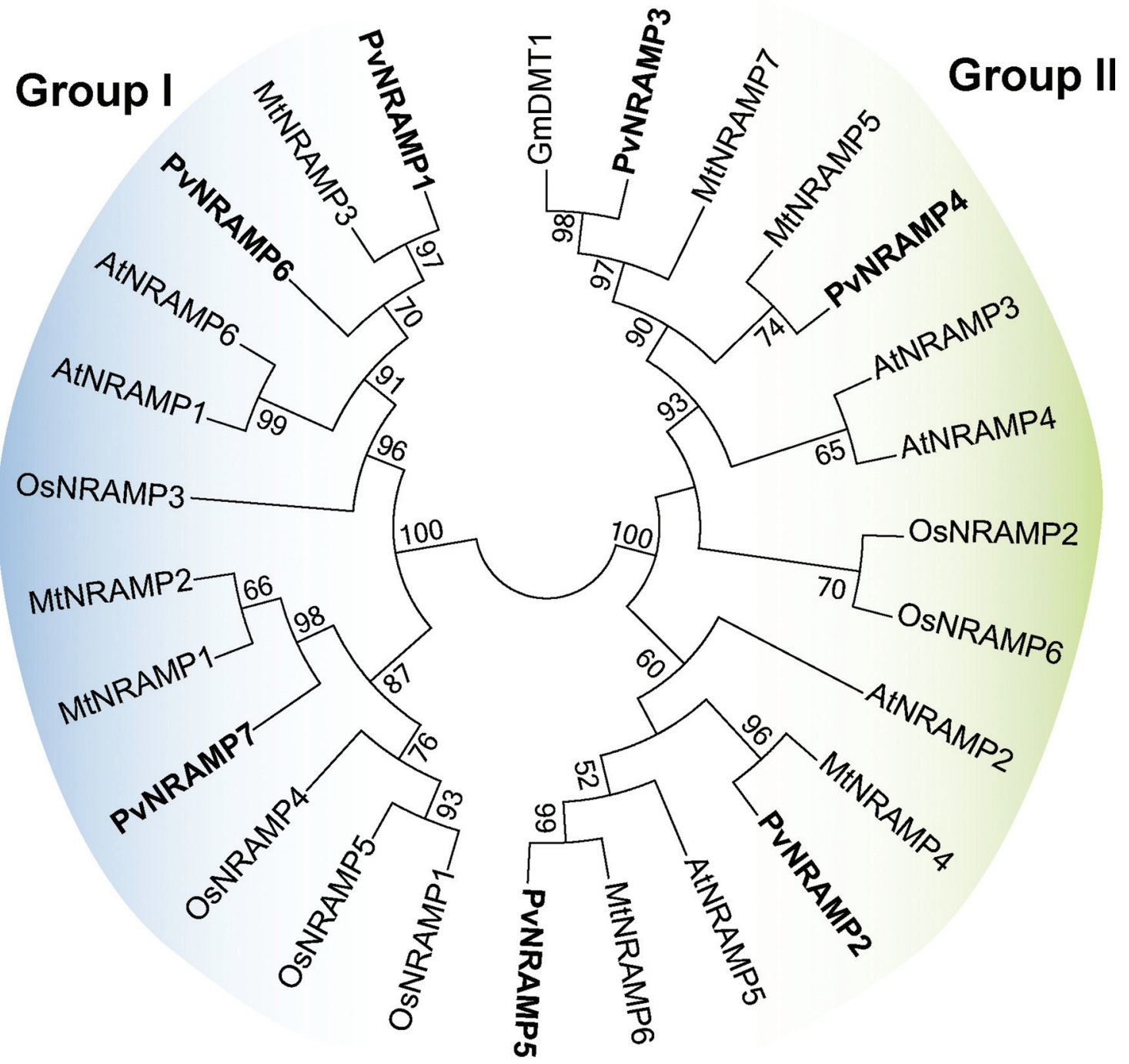

Figure 4 - Phylogenetic tree of NRAMP protein sequences. The unrooted tree was generated based on the Maximum Likelihood statistical method and the numbers at the internal node represent the percentage of 10,000 replicates in which the sequences are grouped in the bootstrap test. The different colors indicate the groups. The PvNRAMP protein sequences are in bold: PvNRAMP1 (Phvul.005G182000); PvNRAMP2 (Phvul.009G069700); PvNRAMP3 (Phvul.003G238600); PvNRAMP4 (Phvul.002G014300); PvNRAMP5 (Phvul.010G110500); and PvNRAMP7 (Phvul.009G127900). MtNRAMP1-MtNRAMP7 (Medtr3g088460, Medtr3g088440, Medtr2g104990, Medtr3g102620, Medtr5g016270, Medtr8g028050, and Medtr4g095075, respectively) and representative plant NRAMP homologues: AtNRAMP1-7 (At1g80830, At1g47240, At2g23150, At5g67330, At4g18790, and At1g15960, respectively) and OsNRAMP1-6 (Os07g0258400, Os03g0208500, Os06g0676000, Os01g0503400, Os07g0257200, and Os12g0581600, respectively). The TjNRAMP4 (Q7XB56), TcNRAMP4 (DQ418489), TcNRAMP3 (EF639294), and GmDMT1 (Glyma17g18010).

\section{Expression analysis of PVNRAMP genes during common bean development}

To gain further insights into biological function of $P v N R A M P s$, their expression levels were investigated using available RNA-Seq data retrieved from different common bean tissues across developmental processes. In Group I, PvNRAMP3 and -4 shared a similar expression pattern, indicating that both were recruited during all stages of common bean development. The expression levels of PvNRAMP2 also exhibited expression in distinct tissues; nevertheless, the levels were lower compared with $P v N R A M P 3,-4$, and -5 (Figure. 6a-c). For Group II, the
PvNRAMP6 and -7 genes were preferentially expressed in the root system, with the highest expression of $P v N R A M P 6$ in active nodules (Figure 6a, b). PvNRAMP1 showed higher expression in reproductive structures, including seeds (Figure 6b, c). At early stages of common bean development, PvNRAMP3 and PvNRAMP4 were differentially up-regulated. $P v N R A M P 3$ was mainly recruited in the suspensor, an embryonic region formed by few cells that connect the embryo to the surrounding endosperm (Kawashima and Goldberg, 2010), while PvNRAMP4 was preferably expressed in the embryo proper (Figure 6c). PvNRAMP5, -6 , and -7 were not expressed (Figure 6c) at this stage of 
a

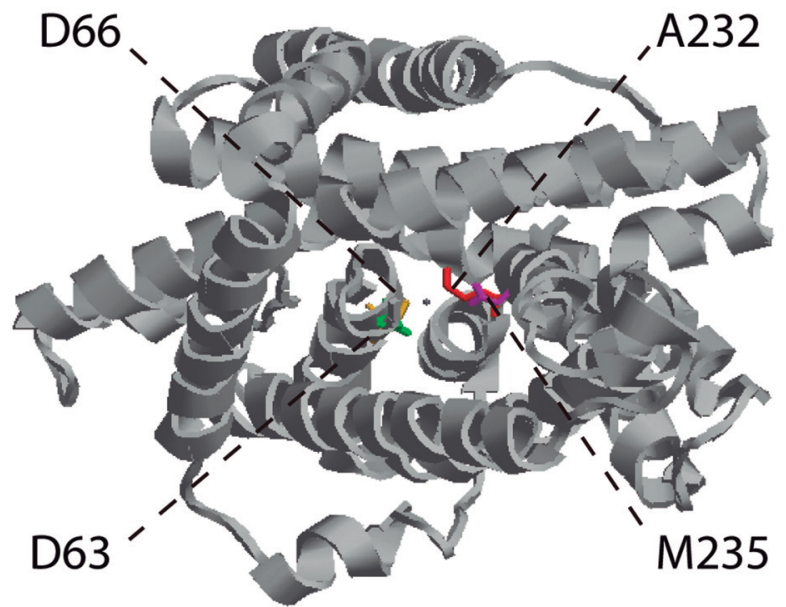

b

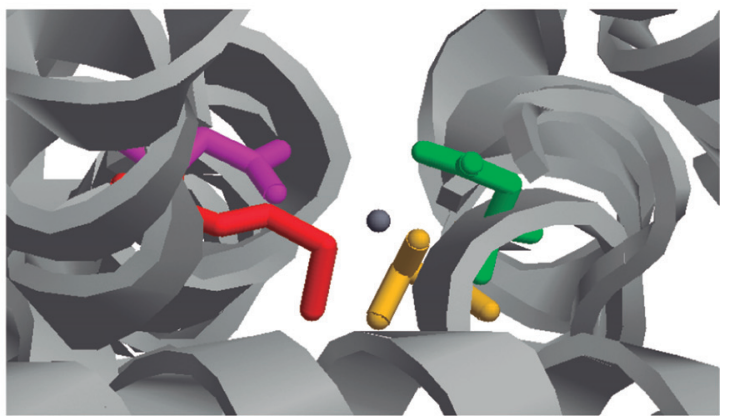

Figure 5 - Predicted 3D structure of NRAMP transporter. Tertiary structure of PvNRAMP7 predicted by SWISS-MODEL software based on the template S. capitis DMT1 (ID: 4wgw.1). (a) The ribbon structure is shown in gray, the amino acids coordinating with manganese (II) ion (shown in blue) are illustrated in different colors: D60 (green); N63 (orange); A232 (red); and M235 (pink). (b) The details of metal coordinating amino acids are displayed.

bean ontogenesis. Therefore, the genes from Group I showed a broad expression across different plant tissues (Figure 6a-c). In contrast, the transporters from Group II exhibited an expression pattern limited to certain tissues.

For further comparisons, the expression levels of the $N R A M P$ homologs in other Fabaceae species were obtained (Figures S3, S4). Analysis of the gene expression atlas of $G$. max (Qin et al., 2017) and M. truncatula (Benedito et al., 2008) indicated that besides GmDMT1 and MtNRAMP1, essential genes for nodulation (Kaiser et al., 2003)(Tejada-Jiménez et al., 2015), GmNRAMP7 (Figure S4) (Qin et al., 2017) and MtNRAMP2 (Figure S3a) were highly expressed during the root interaction with rhizobia. Comparing different tissues at distinct developmental stages, MtNRAMP2 showed an expression level close to MtNRAMP1 (Figure S3a). Investigation of micro-dissected tissues indicated that the biological function of $M T N R A M P 2$ relied on surrounding tissues of rhizobiainfected and nematode-infected cells (Figure S3b). In the phylogenetic branch of GmNRAMP7, MtNRAMP1 and -2 were closest to PvNRAMP7 (Figure S5), that was seen up-regulated in active nodules (Figure 6b and Figure S4). Similar expression patterns were found for $P v N R A M P 6$ (Figure 6b) and for its homologs GmNRAMP5a and GmNRAMP5b (Figure S4, S5). From Group I, the PvNRAMP5 showed weak expression signal in several tissues (Figure 6a), similar to its homolog in soybean (Figure S4). Expression levels in meristematic, vegetative, and reproductive structures of corresponding homologs of PvNRAMP1, -2, -3, -4, and -5 in M. truncatula (Figure S3a, S5) and $G$. $\max$ (Figures S4, S5) were also compared. Analogous to these NRAMP genes in common bean (Figure 6a, b), the homologs in other Fabaceae plants showed similar transcriptional patterns during plant development (Figures $\mathrm{S} 3, \mathrm{~S} 4)$, including the nodule-essential gene GmDMT1 which was preferentially expressed in root hairs and nodules compared with other tissues (Figure S4). Taken together, our data indicated that the biological functions of these genes are highly conserved among the three species.

\section{Transcriptional regulatory elements in PVNRAMP genes}

To get further insights into the putative biological function of NRAMP genes in P. vulgaris, regulatory cis-elements located in the promoter and untranslated regions (UTR) were investigated. First, we searched for Iron Responsive Elements (IREs) motifs in the NRAMP transcriptional sequences. One single IRE regulatory motif (AG TTGTTCATTCAGAGAGTTAGGTAATCAAT) was found in the 3'UTR region of $P v N R A M P 3$, starting at $1584 \mathrm{bp}-1615 \mathrm{bp}$. The GmDMT1, an IRE-contained soybean gene (Kaiser et al., 2003), and PvNRAMP3 were placed at the same branch (Figure S5). To obtain further information of transcriptional regulation of PvNRAMPs, we investigated the presence of regulatory elements in their promoter regions. Regulatory cis-elements of each putative PvNRAMP promoter sequences were identified using the PlantCARE program (Table 2). We observed that the drought- and light-responsive regulatory elements were present in all sequences. The regulatory elements associated with Methyl Jasmonate (MeJa) were limited to the promotors of $P v N R A M P 2,-3$, and -6, whereas the upstream sequences of $P v N R A M P 1$ and -7 showed elements responsive to fungal elicitors. We also observed that all analyzed regions exhibited at least one regulatory element associated with regulation and maintenance of biological processes like hormonal responses. Among them, $P v N R A M P 7$ is the only gene in which the transcriptional response might be regulated by abscisic acid. These results indicated that the regulation of $P v N R A M P$ transcriptional activity may be ac- 
a
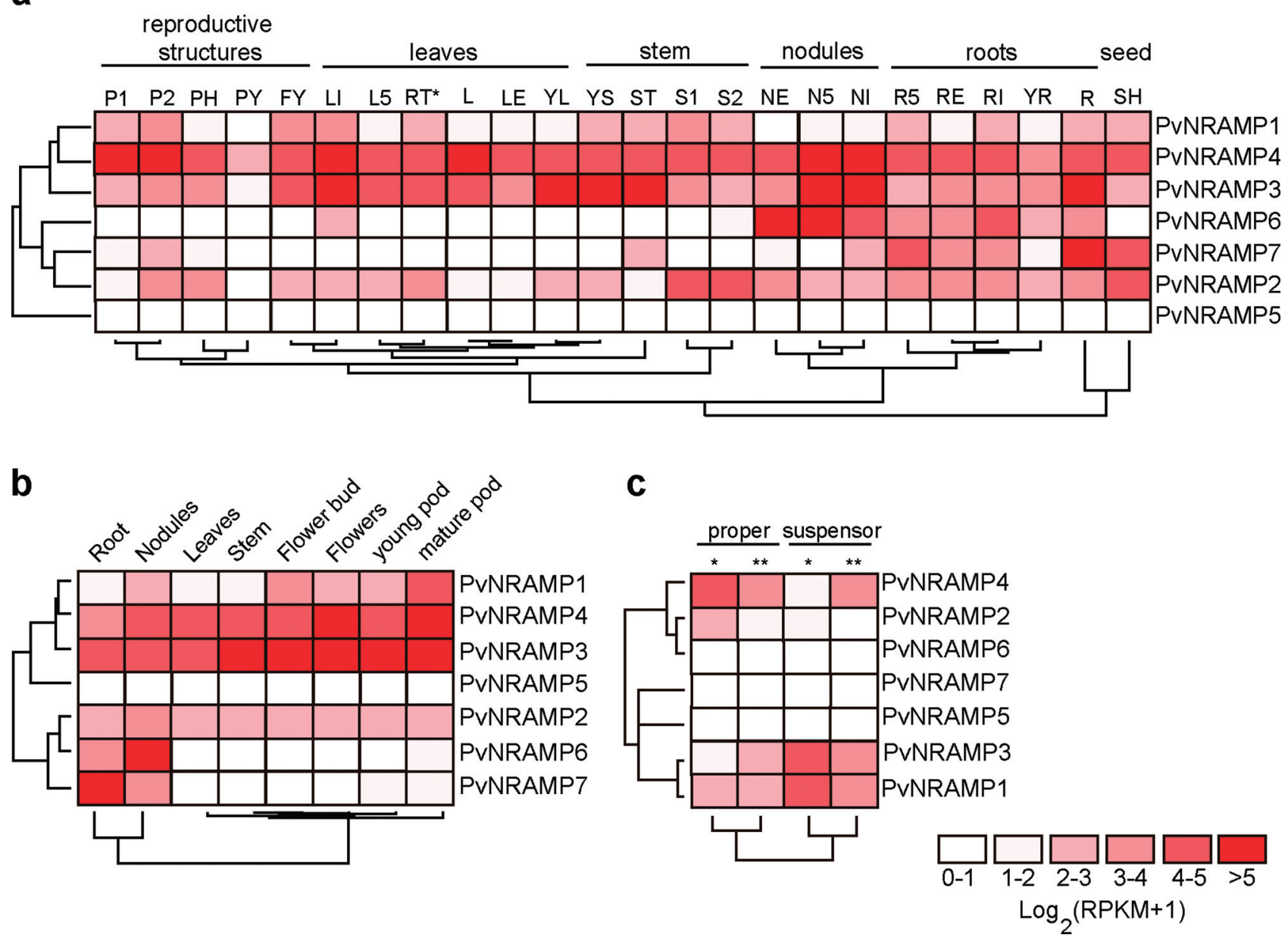

Figure 6 - Expression levels of P. vulgaris NRAMP genes. Heatmaps showing the hierarchical clustering of NRAMP family genes grouped according to the expression patterns of RNA-Seq data collected from different tissues during the development of $P$. vulgaris. Gradient color ranging from white to bright red corresponds to expression values calculated as $\log 2(\mathrm{RPKM}+1)$, as described by the legend at the bottom. (a) RNA-Seq based on gene expression atlas of the common bean (O'Rourke et al., 2014). Expression P1: pods with 10-11 cm; P2: pods with 12-13 cm; PH: pods with $9 \mathrm{~cm}$; PY: young pod; FY: young flower; LI: leaf tissue after 21 days from inoculation of an ineffective rhizobium, L5: leaf tissue 5 days after the inoculation of an effective rhizobium; RT: root tips; SH: heart stage seeds; L: leaf tissue of non-inoculated plant; LE: leaf tissue 21 days after the inoculation of an effective rhizobium; YL: young leaf; YS: young stem; ST: shoot apical meristem; S1: seeds with 6-7 mm; S2: seeds with 8-10 mm; NE: effectively fixing nodules; N5: pre-fixing nodules collected at 5 days after inoculation; NI: ineffective nodules; R5: root system separated from pre-fixing nodules; RE: root separated from effectively fixing nodules; RI: root separated from ineffectively fixing nodules; YR: radicle; R: roots without rhizobium inoculation; RT: root tips; SH: heart stage seeds. (b) 10-day-old root and stem tissues and pool of leaves at different developmental stages (Schmutz et al., 2014). (c) Embryo dissected by laser at heart stage (GSE57535), the expression data in the proper and suspensor embryo tissues are shown. $(*)$ and $(* *)$ asterisks correspond to first and second biological replicates.

tivated during the plant development and by external biotic and abiotic stresses.

\section{Expression of PVNRAMP genes in response to Colletotrichum lindemuthianum infection}

To further investigate the potential involvement of PvNRAMP genes in biotic stress, as suggested by the analysis of regulatory elements, we infected common bean leaves with the pathogenic fungus Colletotrichum lindemuthianum. The transcriptional response of NRAMP genes showed that in general the transporters were downregulated following C. lindemuthianum infection (Table 3). We observed strong suppression with statistical support for
$P v N R A M P 1,-2$ and -3 , while no amplification was observed for the PvNRAMP7 and -5 genes (Table 3). These data suggested a potential interruption of NRAMP-mediated transport in common bean during the pathogen invasion.

\section{Discussion}

Common bean is an important source of nutrients in developing countries. It provides critical metals for human health, such as iron, manganese, zinc, etc. (Beebe et al., 2000). Thus, understanding the mechanisms involved in the accumulation and transport of metals in common bean tissues is relevant for food security. Previous studies have 
Table 2 - List of regulatory cis-elements identified in the putative promoter regions of seven NRAMP genes in P. vulgaris.

\begin{tabular}{|c|c|c|c|c|c|c|c|c|}
\hline Putative biological response & & NRAMP1 & NRAMP2 & NRAMP3 & NRAMP4 & NRAMP5 & NRAMP6 & NRAMP7 \\
\hline \multirow[t]{3}{*}{ Abiotic stress } & Light & 4 & 6 & 7 & 5 & 4 & 6 & 3 \\
\hline & Drought & 1 & 1 & 1 & 1 & 1 & 1 & 1 \\
\hline & Heat/cold & - & - & 1 & 1 & 1 & 1 & - \\
\hline \multirow[t]{3}{*}{ Biotic stress } & MeJa & - & 2 & 2 & - & - & - & - \\
\hline & SA/Defense & 2 & 2 & 2 & 2 & 2 & 2 & 2 \\
\hline & $\begin{array}{l}\text { Fungal } \\
\text { elicitor }\end{array}$ & 1 & - & - & - & - & - & 1 \\
\hline \multirow{8}{*}{$\begin{array}{l}\text { Hormonal response, growth } \\
\text { and development }\end{array}$} & Gibberellin & 1 & - & 1 & - & 1 & - & 1 \\
\hline & Abscisic acid & 1 & 1 & 1 & 1 & 1 & 1 & - \\
\hline & Ethylene & 1 & - & - & - & - & - & - \\
\hline & Cell cycle & - & 1 & - & - & - & - & - \\
\hline & Endosperm & - & 1 & 2 & 2 & 1 & 2 & - \\
\hline & Meristem & - & - & - & 1 & - & 1 & 1 \\
\hline & Leaf & - & - & - & - & - & - & 2 \\
\hline & Seed & - & - & - & - & - & 1 & - \\
\hline
\end{tabular}

Table 3 - Quantitative RT-PCR for PvNRAMPs in C. lindemuthianum-infected leaves.

\begin{tabular}{lcc}
\hline Name & qRT-PCR (fold change) & $p$-value \\
\hline$P v N R A M P 1$ & -3.34 & 0.001 \\
$P v N R A M P 6$ & -2.42 & 0.0615 \\
$P v N R A M P 7$ & No amplification & - \\
$P v N R A M P 2$ & -10.57 & 0.001 \\
$P v N R A M P 3$ & -5.43 & 0.0385 \\
$P v N R A M P 4$ & -1.01 & 0.861 \\
$P v N R A M P 5$ & No amplification & - \\
\hline
\end{tabular}

* Fold change means the gene expression levels in infected leaves divided by the values in non-infected tissue

demonstrated the relevance of the NRAMP carrier family to maintain metal homeostasis in Arabidopsis, rice, and $M$. truncatula (Sebastien and Schroeder, 2004). However, detailed information on this transport family in the common bean was missing. Here, we used a bioinformatics approach to identify the members of NRAMP family in the $P$. vulgaris genome and to determine their biological role during common bean development.

\section{There are two groups of plant NRAMPs that differed} in their origins

The MntH/NRAMP family metal transport emerged as an adaptation to the oxygen-rich environment, and this family is found in the genomes of eukaryotes and prokaryotes (Cellier et al., 1996). The key characteristic of this transporters is the presence of the bacterial Consensus Transport Sequence in the core of the preserved hydrophobic pocket (Cellier et al., 1995). The protein structure reflects the preserved biological role of MntH/NRAMP that conveys the control of the redox metal concentration
(Cellier et al., 2001). In plants, the differences seen among members of the NRAMP family raised the hypotheses that it is a polyphyletic group (Sebastien and Schroeder, 2004). The first group (Group I) has a putative primary amino acid sequence that is apparently closer to MntH/NRAMP from bacteria, whereas the second group (Group II) is more related to those from animals (Sebastien and Schroeder, 2004). Indeed, our phylogenetic data and comparison of protein features, gene structure, and expression patterns are in support of the hypothesis of distinct origins. Similar to AtNRAMP3, -4 in A. thaliana (Lanquar et al., 2005, 2010) and GmNRAMP1a, 2a, 2b and 3a in soybean (Qin et al., 2017), the bacteria-like PvNRAMPs showed a potential function at membranous organelles (Table 1). The putative proteins showed a basic IP, which differed from the animal-like group that showed an acidic isoelectric point (Table 1). Consistently, the fragmented and numerous short exons sequences from Group I contrasted with the concise gene structure seen in Group II (Figure 3 and S1). Additionally, the expression patterns of the NRAMP homologs in Fabaceae also differed between the groups. The stable expression across multiple plant organs suggested that genes from Group II may serve to maintain the biological role in basic cellular processes, transporting metals for growing tissues when they are necessary. In contrast, the genes from Group I showed a higher expression that was generally limited to certain tissues, suggesting a more specific function during plant development. Therefore, our data indicated that NRAMP sequences in plants may be divided into two groups that diverged early during evolution.

\section{Potential role of NRAMP genes in $P$. vulgaris}

Interactions between different organisms are often accompanied by morphological changes, including the formation of specialized organs. For example, parasitic knot 
nematodes provoke the reorganization of root compartments to form giant multinuclear cells at the nematode feeding sites (Jones, 1981). Similarly, symbiotic interactions between nitrogen-fixing bacteria and leguminous plants result in the development of root structures called nodules (Masson-Boivin et al., 2009), which require an intense iron mobilization as cofactor of critical enzymes involved in nodulation (Tang et al., 1990). During nodule formation, when drastic morphological changes occur, the surrounding cells harbor transporter proteins to fully supply the newly-formed organ with necessary nutrients. The up-regulation of MtNRAMP2 limited to the region that is circumjacent to the rhizobia-infecting zone and root galls (Figure S3) suggests a conserved function of this protein as a carrier to supply minerals for plant-interacting organisms throughout their life cycle. The closest gene to MtNRAMP2 in amino acid sequence is MtNRAMP1, which is recruited for both iron and manganese uptake for nodulation in $M$. truncatula (Tejada-Jiménez et al., 2015). Its homolog in soybean, GmNRAMP7 (Figure S5) gene is highly regulated during nodulation (Figure S4), activated upon iron starvation and suppressed under iron toxicity (Qin et al., 2017). Our data comparison indicated that orthologous pairs among Fabaceae maintained similar expression patterns, suggesting a potential conserved biological function. The predicted tertiary structure of PvNRAMP7 and -6 (Figures 5, S2), their high similarities with the homologs MtNRAMP1 (Figures S3, S5) and GmNRAMP7 (Figures $\mathrm{S} 4, \mathrm{~S} 5)$ in terms of expression patterns allowed us to infer that $P v N R A M P 7$ and -6 might be the NRAMP transporters used for iron/manganese trafficking involved in initiating the nodules in $P$. vulgaris.

Plants adopted two strategies for iron uptake from the environment (Marschner and Römheld, 1994). The first strategy, found in all the plants except Poaceae, is that root cells release into the rhizosphere substances that reduce the iron forms so that they can be absorbed by carrier proteins, such as AtNRAMP1 (Curie et al., 2000), MtNRAMP1 (Tejada-Jiménez et al., 2015) and GmDMT1 (Kaiser et al., 2003). The second strategy is followed by the Poaceae family, which release into the soil the Fe-chelating molecules known as siderophores, where specific transporters facilitate the entry of the ferric-iron-siderophores complex into the plant cell (Marschner and Römheld, 1994).

Most genes encoding iron transporters harbor an IRE motif that plays a direct role in iron regulation (Muckenthaler et al., 2008). Briefly, under iron deficiency, the IRE motif becomes an available binding site for iron-regulating proteins (IRPs) responsible for stabilizing the mRNA, allowing an increase in the transcriptional level (Muckenthaler et al., 2008). Several iron-regulated plant genes contain IRE motifs at their UTRs (Petit et al., 2001; Vert et al., 2001, 2002), although the role of the IRE/IRP mechanism in iron homeostasis in plants is controversial (Arnaud et al., 2007). The iron-induced GmDMT1 gene encoding an NRAMP transporter shows a single IRE motif in its 3'UTR, and it is recruited to absorb iron into soybean root nodules (Kaiser et al., 2003). In P. vulgaris, only the PvNRAMP3 transcript showed a single IRE motif in its 3 'UTR, associating this gene with iron metabolism in beans. The expression spectrum ranging from embryo to mature pods (Figure $6 \mathrm{a}-\mathrm{c})$, including the nodules, indicated that this function is widely required and that it is not limited to the plantrhizobia interaction.

In the early stages of plant development, embryo growth is one of the critical events in which the metal transporters are intensively required (Kawashima and Goldberg, 2010). During the embryo formation, a set of cells called suspensor maintains the embryo connected to the surrounding tissue. The basic function of the suspensor is to transport necessary metabolites to embryo proper. The differential transcriptional regulation of NRAMP genes in $P$. vulgaris indicated that three genes are recruited during the early stages of bean formation (Figure 6c). PvNRAMP4 is up-regulated in suspensor cells and might facilitate the regulation of the concentration of divalent metals from endosperm to embryo, while PvNRAMP1 and -3 might be acting in the embryo proper to allocate the metals to needed cell compartments.

Besides the recruitment of NRAMP transporters during plant development and host-microorganism interactions, members of this family actively participate in the accumulation of toxic metals in plants (Thomine et al., 2000; Mizuno et al., 2005; Oomen et al., 2009). The pollution in water bodies and river tributaries that supply agricultural fields caused increased concern over the accumulation of toxic metals in crop cultivation (Clemens and Ma, 2016). OsNRAMP1 is directly associated with arsenic (As) and cadmium (Cd) uptake in rice (Takahashi et al., 2011; Tiwari et al., 2014), while TjNRAMP4, TcNRAMP3 and -4 are recruited in the heavy-metal-tolerant species $T$. japonicum (Mizuno et al., 2005) and T. caerulescens (Oomen et al., 2009). In the common bean, few studies have investigated the impact of metal pollutants in plant metabolism. Thus, the identification and characterization of PvNRAMP transporters provided in this study may help us to elucidate the involvement of these proteins in toxic metal uptake and accumulation in beans.

The fungal pathogen $C$. lindemuthianum is the causal agent of anthracnose disease, which strongly affects bean productivity (Couto et al., 2005; Aragão et al., 2011). This pathogen adopted a hemibiotrophic lifestyle, varying from an early biotrophic phase to a necrotrophic phase (Perfect $e t$ al., 1999). During the biotrophic stage, the pathogenic fungus cohabitating with living plant cells absorbs nutrients from the host (Perfect et al., 1999; Gan et al., 2013). In vertebrates, one of the host strategies to block the pathogenic progress is to restrict the availability of essential metals such as iron, zinc, manganese and copper (Kehl-Fie and Skaar, 2010). Thus, to withhold the pathogenic growth, the host transcriptional machinery suppresses the expression of the metal NRAMP1 transporter (Wessling-Resnick, 2015). 
This nutritional immunity strategy through metal retention found in vertebrates might also occur in plants. The modulation of two isoforms of OsNRAMP6 by a microRNA during Magnaporthe oryzae infection was described as contributing to disease resistance (Campo et al., 2013; Peris-Peris et al., 2017). Here, we observed that three members of the NRAMP family in P. vulgaris (PvNRAMP1, -2 and -3) were suppressed upon $C$. lindemuthianum invasion during its biotrophic stage (Table 3 ). This data may indicate that PvNRAMP transporters may play a role in $P$. vulgaris as a defense strategy, retaining the accessibility of metals essential for the pathogenic growth, thereby restricting disease advance in plant tissues.

\section{Conclusions}

Common bean has seven members of the NRAMP family. The phylogenetic analysis using sequences from representative species indicated that there are two NRAMP groups in $P$. vulgaris. An expression pattern comparison of NRAMP genes in Fabaceae from multiple tissues at different developmental stages indicated a conserved biological function among NRAMP homologs. The transcriptional level analysis revealed that $P v N R A M P 6$ and -7 may have a role during symbiosis with beneficial microorganism, whereas PvNRAMP1, -2, -3, -4 and -5 might be required for general metal homeostasis during all developmental stages of the common bean. The qRT-PCR analysis indicated that $N R A M P$ genes are not required during infection by the pathogen $C$. lindemuthianum. Taken together, the systematic genome-wide-analysis of NRAMP genes in the $P$. vulgaris genome, supplies basic information on their role in regulating metal homeostasis during development and interaction with microorganisms in common bean.

\section{Acknowledgments}

The authors thank Dr. Margarida Ito from the Agronomic Institute of Campinas for kindly providing $\mathrm{g} C$. lindemuthianum isolates used in this study. The project received financial support from the Science Without Borders Program from the Brazilian Federal Government (88887.092433/2015-00). DGGC, LRO and GCF received scholarships from the São Paulo State Research Foundation (FAPESP 2013/06301-2, 2016/00385-8 and 2016/00359-7). LML obtained a scholarship from the Coordination for the Improvement of Higher Education Personnel (CAPES 88887.092433/2015-00).

\section{References}

Altschul S (1997) Gapped BLAST and PSI-BLAST: A new generation of protein database search programs. Nucleic Acids Res 25:3389-3402.

Aragão FJL, Brondani RPV and Burle ML (2011) Phaseolus. In: Kole C (ed) Wild Crop Relatives: Genomic and Breeding Resources. Springer, Berlin, pp 223-236.
Arnaud N, Ravet K, Borlotti A, Touraine B, Boucherez J, Fizames C, Briat JF, Cellier F and Gaymard F (2007) The ironresponsive element (IRE)/iron-regulatory protein 1 (IRP1)-cytosolic aconitase iron-regulatory switch does not operate in plants. Biochem J 405:523-531.

Beebe S, Gonzalez AV and Rengifo J (2000) Research on trace minerals in the common bean. Food Nutr Bull 21:387-391.

Belouchi A, Kwan T and Gros P (1997) Cloning and characterization of the OsNramp family from Oryza sativa, a new family of membrane proteins possibly implicated in the transport of metal ions. Plant Mol Biol 33:1085-1092.

Benedito VA, Torres-Jerez I, Murray JD, Andriankaja A, Allen S, Kakar K, Wandrey M, Verdier J, Zuber H, Ott T, et al. (2008) A gene expression atlas of the model legume Medicago truncatula. Plant J 55:504-513.

Bennink MR (2002) Consumption of black beans and navy beans (Phaseolus vulgaris) reduced azoxymethane-induced colon cancer in rats. Nutr Cancer 44:60-65.

Borges A, Tsai SM and Caldas DGG (2012) Validation of reference genes for RT-qPCR normalization in common bean during biotic and abiotic stresses. Plant Cell Rep 31:827-838.

Bouchenak M and Lamri-Senhadji M (2013) Nutritional quality of legumes, and their role in cardiometabolic risk prevention: A review. J Med Food 16:185-198.

Brear EM, Day DA and Smith PMC (2013) Iron: An essential micronutrient for the legume-rhizobium symbiosis. Front Plant Sci 4:359.

Broughton WJ, Hernández G, Blair M, Beebe S, Gepts P and Vanderleyden J (2003) Beans (Phaseolus spp.) - model food legumes. Plant Soil 252:55-128.

Campillos M, Cases I, Hentze MW and Sanchez M (2010) SIREs: Searching for iron-responsive elements. Nucleic Acids Res 38:W360-W367.

Campo S, Peris-Peris C, Siré C, Moreno AB, Donaire L, Zytnicki M, Notredame C, Llave C and San Segundo B (2013) Identification of a novel microRNA (miRNA) from rice that targets an alternatively spliced transcript of the Nramp6 (Natural resistance-associated macrophage protein 6) gene involved in pathogen resistance. New Phytol 199:212-227.

Cellier MFM (2012) NRAMP: From sequence to sructure and mechanism of divalent metal import. In: Lutsenko $\mathrm{S}$ and Argüello JM (eds) Metal transporters. Elsevier-Academic Press, Oxford, p 435.

Cellier M, Privé G, Belouchi A, Kwan T, Rodrigues V, Chia W and Gros P (1995) NRAMP defines a family of membrane proteins. Proc Natl Acad Sci U S A 92:10089-10093.

Cellier M, Belouchi A and Gros P (1996) Resistance to intracellular infections: comparative genomic analysis of Nramp. Trends Genet 12:201-204.

Cellier MF, Bergevin I, Boyer E and Richer E (2001) Polyphyletic origins of bacterial NRAMP transporters. Trends Genet 17:365-370.

Clemens S and Ma JF (2016) Toxic heavy metal and metalloid accumulation in crop plants and foods. Annu Rev Plant Biol 67:489-512.

Couto MA, Bosco J, Santos D, De Fátima A and Abreu B (2005) Selection of Carioca type common bean lines with anthracnose and angular leaf spot-resistance. Crop Breed Appl Biotechnol 5:325-332. 
Curie C, Alonso JM, Le Jean M, Ecker JR and Briat JF (2000) Involvement of NRAMP1 from Arabidopsis thaliana in iron transport. Biochem J 347:749-755.

Damiani I, Baldacci-Cresp F, Hopkins J, Andrio E, Balzergue S, Lecomte P, Puppo A, Abad P, Favery B and Hérouart D (2012) Plant genes involved in harbouring symbiotic rhizobia or pathogenic nematodes. New Phytol 194:511-522.

Dordas C (2008) Role of nutrients in controlling plant diseases in sustainable agriculture: Agron Sustain Dev 28:33-46.

Ehrnstorfer IA, Geertsma ER, Pardon E, Steyaert J and Dutzler R (2014) Crystal structure of a SLC11 (NRAMP) transporter reveals the basis for transition-metal ion transport. Nat Struct Mol Biol 21:990-996.

Emanuelsson O, Brunak S, von Heijne G and Nielsen H (2007) Locating proteins in the cell using TargetP, SignalP and related tools. Nat Protoc 2:953-971.

Fitsanakis VA, Zhang N, Garcia S and Aschner M (2010) Manganese $(\mathrm{Mn})$ and Iron $(\mathrm{Fe})$ : Interdependency of transport and regulation. Neurotox Res 18:124-131.

Gage DJ (2004) Infection and invasion of roots by symbiotic, nitrogen-fixing rhizobia during nodulation of temperate legumes. Microbiol Mol Biol Rev 68:280-300.

Gan P, Ikeda K, Irieda H, Narusaka M, O'Connell RJ, Narusaka Y, Takano Y, Kubo Y and Shirasu K (2013) Comparative genomic and transcriptomic analyses reveal the hemibiotrophic stage shift of Colletotrichum fungi. New Phytol 197:1236-1249.

Geil PB and Anderson JW (1994) Nutrition and health implications of dry beans: A review. J Am Coll Nutr 13:549-558.

Gepts P, Aragão FJL, Barros E de, Blair MW, Brondani R, Broughton W, Galasso I, Hernández G, Kami J, Lariguet P, et al. (2008) Genomics of Phaseolus beans, a major source of dietary protein and micronutrients in the tropics. In: Moore PH and Ming R (eds) Genomics of Tropical Crop Plants. Springer, New York, pp 113-143.

Gunshin H, Allerson CR, Polycarpou-Schwarz M, Rofts A, Rogers JT, Kishi F, Hentze MW, Rouault TA, Andrews NC and Hediger MA (2001) Iron-dependent regulation of the divalent metal ion transporter. FEBS Lett 509:309-316.

Hall JL and Williams LE (2003) Transition metal transporters in plants. J Exp Bot 54:2601-2613.

Hu B, Jin J, Guo A-Y, Zhang H, Luo J and Gao G (2015) GSDS 2.0: An upgraded gene feature visualization server. Bioinformatics 31:1296-1297.

Iolascon A and De Falco L (2009) Mutations in the gene encoding DMT1: Clinical presentation and treatment. Semin Hematol 46:358-370.

Ishimaru Y, Takahashi R, Bashir K, Shimo H, Senoura T, Sugimoto K, Ono K, Yano M, Ishikawa S, Arao T, et al. (2012) Characterizing the role of rice NRAMP5 in manganese, iron and cadmium transport. Sci Rep 2:286.

Jones KM, Kobayashi H, Davies BW, Taga ME and Walker GC (2007) How rhizobial symbionts invade plants: the Sinorhizobium-Medicago model. Nat Rev Micro 5:619-633.

Jones MGK (1981) Host cell responses to endoparasitic nematode attack: Structure and function of giant cells and syncytia. Ann Appl Biol 97:353-372.

Kaiser BN, Moreau S, Castelli J, Thomson R, Lambert A, Bogliolo S, Puppo A and Day DA (2003) The soybean NRAMP homologue, GmDMT1, is a symbiotic divalent metal transporter capable of ferrous iron transport. Plant J 35:295-304.
Kawashima T and Goldberg RB (2010) The suspensor: Not just suspending the embryo. Trends Plant Sci 15:23-30.

Kehl-Fie TE and Skaar EP (2010) Nutritional immunity beyond iron: a role for manganese and zinc. Curr Opin Chem Biol $14: 218-224$.

Krogh A, Larsson B, von Heijne G and Sonnhammer EL (2001) Predicting transmembrane protein topology with a hidden Markov model: Application to complete genomes. J Mol Biol 305:567-580.

Kumar S, Stecher G, Tamura K (2016) MEGA7: Molecular Evolutionary Genetics Analysis Version 7.0 for Bigger Datasets. Mol Biol Evol 33:1870-1874.

Lanquar V, Lelièvre F, Bolte S, Hamès C, Alcon C, Neumann D, Vansuyt G, Curie C, Schröder A, Krämer U, et al. (2005) Mobilization of vacuolar iron by AtNRAMP3 and AtNRAMP4 is essential for seed germination on low iron. EMBO J 24:4041-4051.

Lanquar V, Ramos MS, Lelièvre F, Barbier-Brygoo H, KriegerLiszkay A, Krämer U and Thomine S (2010) Export of vacuolar manganese by AtNRAMP3 and AtNRAMP4 is required for optimal photosynthesis and growth under manganese deficiency. Plant Physiol 152:1986-1999.

Lescot M, Déhais P, Thijs G, Marchal K, Moreau Y, Van de Peer Y, Rouzé P and Rombauts S (2002) PlantCARE, a database of plant cis-acting regulatory elements and a portal to tools for in silico analysis of promoter sequences. Nucleic Acids Res 30:325-327.

Marschner H and Römheld V (1994) Strategies of plants for acquisition of iron. Plant Soil 165:261-274.

Masson-Boivin C, Giraud E, Perret X and Batut J (2009) Establishing nitrogen-fixing symbiosis with legumes: How many rhizobium recipes? Trends Microbiol 17:458-466.

Mizuno T, Usui K, Horie K, Nosaka S, Mizuno N and Obata H (2005) Cloning of three ZIP/Nramp transporter genes from a $\mathrm{Ni}$ hyperaccumulator plant Thlaspi japonicum and their Ni2+-transport abilities. Plant Physiol Biochem 43:793-801.

Muckenthaler MU, Galy B and Hentze MW (2008) Systemic iron homeostasis and the Iron-Responsive Element/Iron-Regulatory Protein (IRE/IRP) regulatory network. Annu Rev Nutr 28:197-213.

Nevo Y and Nelson N (2006) The NRAMP family of metal-ion transporters. Biochim Biophys Acta - Mol Cell Res 1763:609-620.

O'Rourke JA, Iniguez LP, Fu F, Bucciarelli B, Miller SS, Jackson SA, McClean PE, Li J, Dai X, Zhao PX, et al. (2014) An RNA-Seq based gene expression atlas of the common bean. BMC Genomics 15:866.

Oomen RJFJ, Wu J, Lelièvre F, Blanchet S, Richaud P, Barbier-Brygoo H, Aarts MGM and Thomine S (2009) Functional characterization of NRAMP3 and NRAMP4 from the metal hyperaccumulator Thlaspi caerulescens. New Phytol 181:637-650.

Perfect SE, Hughes HB, O'Connell RJ and Green JR (1999) Colletotrichum: A model genus for studies on pathology and fungal-plant interactions. Fungal Genet Biol 27:186-198.

Peris-Peris C, Serra-Cardona A, Sánchez-Sanuy F, Campo S, Ariño J and San Segundo B (2017) Two NRAMP6 isoforms function as iron and manganese transporters and contribute to disease resistance in rice. Mol Plant-Microbe Interact 30:385-398. 
Petit JM, van Wuytswinkel O, Briat JF and Lobreaux S (2001) Characterization of an Iron-dependent regulatory sequence involved in the transcriptional control of AtFer land ZmFer 1 plant ferritin genes by iron. J Biol Chem 276:5584-5590.

Pfaffl MW, Horgan GW and Dempfle L (2002) Relative expression software tool (REST(C)) for group-wise comparison and statistical analysis of relative expression results in realtime PCR. Nucleic Acids Res 30:e36

Qin L, Han P, Chen L, Walk TC, Li Y, Hu X, Xie L, Liao H and Liao X (2017) Genome-wide identification and expression analysis of NRAMP family genes in soybean (Glycine max L.). Front Plant Sci 8:1436.

Ramakers C, Ruijter JM, Deprez RHL and Moorman AFM (2003) Assumption-free analysis of quantitative real-time polymerase chain reaction (PCR) data. Neurosci Lett 339:62-66.

Ravet K, Touraine B, Boucherez J, Briat JF, Gaymard F and Cellier F (2009) Ferritins control interaction between iron homeostasis and oxidative stress in Arabidopsis. Plant $\mathrm{J}$ 57:400-412.

Reich M, Liefeld T, Gould J, Lerner J, Tamayo P and Mesirov JP (2006) GenePattern 2.0. Nat Genet 38:500-501.

Schmutz J, McClean PE, Mamidi S, Wu GA, Cannon SB, Grimwood J, Jenkins J, Shu S, Song Q, Chavarro C, et al. (2014) A reference genome for common bean and genome-wide analysis of dual domestications. Nat Genet 46:707-713.

Sebastien T and Schroeder JI (2004) Plant metal transporters with homology to proteins of the NRAMP family. In: Cellier M and Gros P (eds) The NRAMP family. Kluwer Academic Publishers-Plenum Publishers, New York, pp 113-123.

Shawki A, Knight PB, Maliken BD, Niespodzany EJ and Mackenzie B (2012) H+-coupled divalent metal-ion transporter-1. Curr Top Membr 70:169-214.

Takahashi R, Ishimaru Y, Senoura T, Shimo H, Ishikawa S, Arao T, Nakanishi H and Nishizawa NK (2011) The OsNRAMP1 iron transporter is involved in $\mathrm{Cd}$ accumulation in rice. J Exp Bot 62:4843-4850.

Tang C, Robson AD and Dilworth MJ (1990) The role of iron in nodulation and nitrogen fixation in Lupinus angustifolius L. New Phytol 114:173-182.

Tejada-Jiménez M, Castro-Rodríguez R, Kryvoruchko I, Lucas MM, Udvardi M, Imperial J and González-Guerrero M (2015) Medicago truncatula Natural Resistance-Associated Macrophage Protein 1 is required for iron uptake by rhizobia-infected nodule cells. Plant Physiol 168:258-272.

Thomine S, Wang R, Ward JM, Crawford NM and Schroeder JI (2000) Cadmium and iron transport by members of a plant metal transporter family in Arabidopsis with homology to NRAMP genes. Proc Natl Acad Sci U S A 97:4991-4996.

Thompson JD, Gibson TJ and Higgins DG (2002) Multiple sequence alignment using ClustalW and ClustalX. Curr Protoc Bioinformatics Chapter 2:Unit 2.3.

Tiwari M, Sharma D, Dwivedi S, Singh M, Tripathi RD and Trivedi PK (2014) Expression in Arabidopsis and cellular localization reveal involvement of rice NRAMP, OsNRAMP1, in arsenic transport and tolerance. Plant Cell Environ 37:140-152.

Untergasser A, Nijveen H, Rao X, Bisseling T, Geurts R and Leunissen JAM (2007) Primer3Plus, an enhanced web interface to Primer3. Nucleic Acids Res 35:W71-W74.

Vatansever R, Filiz E and Ozyigit II (2016) In silico analysis of Mn transporters (NRAMP1) in various plant species. Mol Biol Rep 43:151-163.

Vert G, Briat JF and Curie C (2001) Arabidopsis IRT2 gene encodes a root-periphery iron transporter. Plant J 26:181-189.

Vert G, Grotz N, Dédaldéchamp F, Gaymard F, Guerinot M Lou, Briat JF and Curie C (2002) IRT1, an Arabidopsis transporter essential for iron uptake from the soil and for plant growth. Plant Cell 14:1223-1233.

Victoria FC, Bervald CMP, da Maia LC, de Sousa RO, Panaud O and de Oliveira AC (2012) Phylogenetic relationships and selective pressure on gene families related to iron homeostasis in land plants. Genome 55:883-900.

Wessling-Resnick M (2015) NRAMP1 and other transporters involved in metal withholding during infection. J Biol Chem 290:18984-18990.

Wu D, Yamaji N, Yamane M, Kashino-Fujii M, Sato K and Feng Ma J (2016) The HvNramp5 transporter mediates uptake of cadmium and manganese, but not iron. Plant Physiol 172:1899-1910.

Xia J, Yamaji N, Kasai T and Ma JF (2010) Plasma membrane-localized transporter for aluminum in rice. Proc Natl Acad Sci U S A 107:18381-18385.

Yamaji N, Sasaki A, Xia JX, Yokosho K and Ma JF (2013) A node-based switch for preferential distribution of manganese in rice. Nat Commun 4:1306-1313.

\section{Supplementary Material}

The following online material is available for this article:

Figure S1 - Schematic structure of NRAMP genes in $P$. vulgaris, M. truncatula, A. thaliana, O. sativa and G. max. Figure S2 - Putative 3D structure of NRAMP transporter. Figure S3 - Expression levels of NRAMP genes in $M$. truncatula.

Figure S4 - The expression of NRAMP genes in vegetative and reproductive tissues in soybean.

Figure S5 - Phylogenetic tree of NRAMP genes in Fabaceae.

Table S1 - Gene specific primers for P. vulgaris NRAMP genes.

Associate Editor: Everaldo Gonçalves de Barros

License information: This is an open-access article distributed under the terms of the Creative Commons Attribution License (type CC-BY), which permits unrestricted use, distribution and reproduction in any medium, provided the original article is properly cited. 